This is the peer reviewed version of the following article: Mecerreyes, D., Porcarelli, L., Casado, N., Innovative Polymers for NextGeneration Batteries. Macromol. Chem. Phys. 2020, 221, 1900490, which has been published in final form at https:// doi.org/10.1002/macp.201900490. This article may be used for non-commercial purposes in accordance with Wiley Terms and Conditions for Use of Self-Archived Versions.

\title{
Innovative Polymers for Next-Generation Batteries
}

\author{
David Mecerreyes, ${ }^{a, b, *}$ Luca Porcarelli, ${ }^{a}$ and Nerea Casado ${ }^{a}$ \\ aPOLYMAT University of the Basque Country UPV/EHU Paseo Manuel de Lardizabal 3, 20018 Donostia- \\ San Sebastián, Spain \\ bIKERBASQUE Basque Foundation for Science 48011 Bilbao, Spain \\ *Corresponding Author: david.mecerreyes@ehu.es
}

\begin{abstract}
Lithium-ion batteries are part of modern life, being present in daily-used objects such as mobile phones, tablets, computers, watches, sport accessories, electric scooters, and cars. The nextgeneration batteries require the development of innovative polymers that help to improve their performance in terms of power density, cyclability, raw materials' availability, low weight, printability, flexibility, sustainability, or security. This article highlights recent developments in the area of redoxactive, electronic/ionic conducting polymers. This includes the development of innovative binders for electrodes, polymer electrolytes, and redox polymers. All these new polymer developments are leading to new battery technologies such as metal-polymer batteries, organic batteries, polymer-air, and redox-flow batteries, which are expected to complement the current lithium-ion technologies in the future.
\end{abstract}

Cite This: Macromol. Chem. Phys. 2020, 221, 1900490

DOI: 10.1002/macp.201900490 


\section{Role of Polymers in Batteries}

Batteries are part of our modern life being present in daily-used objects such as mobile phones, tablets, computers, watches, sport accessories, electric scooters, or cars to name a few. The leading rechargeable battery technology nowadays is lithium ion whose important discovery in the 1980s was recognized with the Nobel Prize in Chemistry in 2019.1 Although polymers are not in the active mechanism of the lithium ion battery, in every commercial battery nowadays there are polymers present as inactive components such as binders for the electrodes or porous separators. Nowadays the race is open worldwide to develop nextgeneration batteries which improve the performance of lithium-ion batteries and present different advantages such as power density, cyclability, raw materials availability, low weight, printability, flexibility, security, or price. All this will be crucial in the future energetic scenario if the actual trend in the use of renewable and green energies goes on. In this race, polymers will enable materials which may be also used as active ingredients of the batteries. The aim of this trend article is to highlight recent developments in innovative polymers which may play a role in the next-generation batteries.

The simple working principle of a rechargeable battery is shown in Figure 1. A battery consists of one or more electrochemical cells, which converts stored chemical energy directly into electrical energy. A battery is a device that produces electrons through electrochemical reactions, and contains three main components; one positive electrode known as cathode, a negative one known as anode, and a third one between both electrodes that is known as electrolyte. Within the electrolyte a metal salt is dissolved and typically Li+ moves between the two electrodes during the charge and discharge processes. The next-generation battery technologies will result from the use of high performing materials as electrodes including metals, sulfur, or air, as well as different ion chemistries in the electrolyte (sodium, zinc, calcium, aluminum, magnesium, etc.). 2

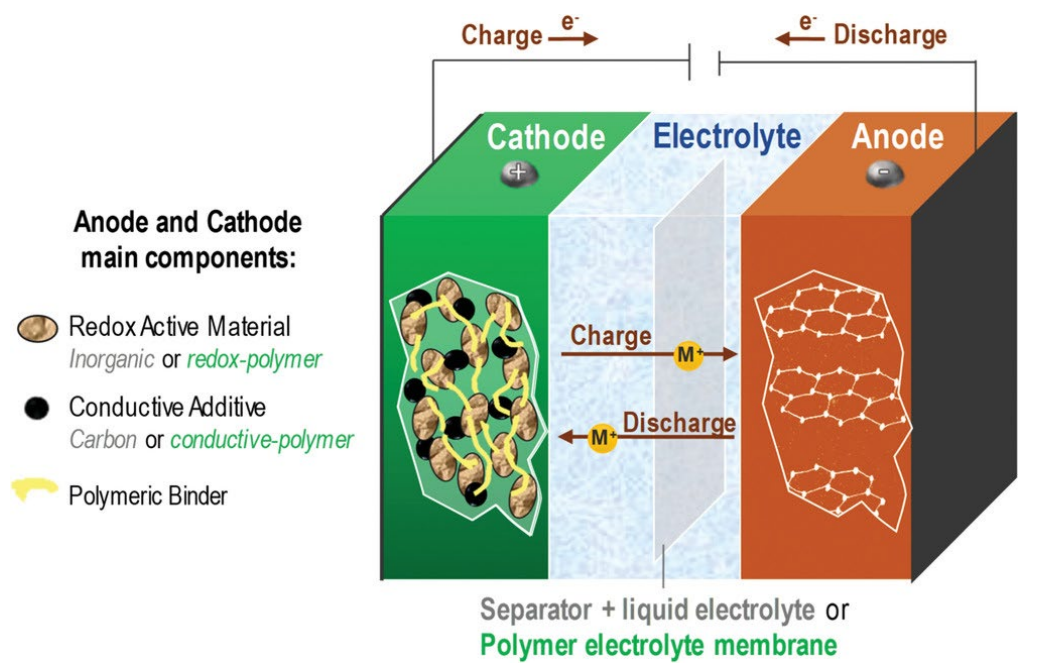

Figure 1 Representative scheme of an actual battery with its components (in black) and the potential role of polymer components (in green). 
As indicated in the first paragraph, polymers play an inactive role such as separators among the electrodes or binders of the electrode materials in most of the actual lithium-ion batteries. However, they are receiving more and more attention as electronically or ionically active components in batteries such as redox-active and conductive binders, polymer electrolytes, and electrodes of new organic battery technologies. In the next paragraphs we will highlight some recent developments by our group and others which can serve as examples of the actual trends in the development of polymers for next-generation batteries.

\section{Polymer Separators and Binders}

The function of the separator is to avoid contact and consequent internal short circuit between the electrodes and to allow fast ion migration of the salt dissolved in the liquid electrolytes. Commercial separators are commonly based on microporous membranes made of polyethylene, polypropylene or by combining different polymers in multi-layer fims. Although these membranes are optimized for electrolytes based on organic carbonates, they are not always effective with new electrolyte materials such as ionic liquids. In particular, poor wettability and low thermal stability is a common issue within this class of materials. Thus, new separators are another important research area in polymers for the next generation of batteries. A clear example is the activities related to the chemical modification of current porous separators by polymer grafting and innovative coating techniques which have been extensively pursued in the past years. Furthermore, non-woven separators formed by entangled fibers are another emerging class of separator materials that are being investigated. The preparation of mats by conventional dry methods or wet methods, such as electrospinning is a very active topic of research (Figure 2). Finally, composite membranes are also under investigation where inorganic particles play the role of fillers or surface coating which improve some of the properties such as liquid electrolyte uptake or its retention. $\underline{3}$

The function of a binder is to provide structural integrity to the electrode and to ensure good contact between the electrode, the redox-active material, and the conductive material. Although binders only occupy $2-5 \%$ of the mass in a commercial electrode configuration, the binder material is one of the most crucial electrode components for improved cell performance, especially for cycle life. Without the binder, the active materials will lose contact with the current collector, resulting in capacity loss. Poly(vinylidene difluoride) (PVDF) and its copolymers are the most widely used binders for Li-ion cells. This is due to its good electrochemical stability and binding capability, as well as its ability to absorb electrolyte for facile transport of lithium to the active material surface. However, PVDF requires the usage of toxic and expensive organic solvents such as $\mathrm{N}$-methyl pyrrolidone in the electrode processing. $\underline{4}$ Alternatively, aqueous binders and electrode inks containing water have been developed in the past years. Among these aqueous binders carbomethyl cellulose and other biopolymers, poly(acrylic acid), SBR latexes, and poly(ethylene oxide) (PEO) were the most 
successful ones. $\underline{5}$ It is worth to note that some companies have also developed PVDF aqueous formulations to be used as binders. $\underline{6}$

An even more interesting approach is to use binders that have an active functional role in the electrode. To this end, several works reported the use of conducting polymers such as PEDOT/PSS or other polythiophenes in different electrode formulations. $\underline{7}$ The main advantage of the conductive polymer is that it may have the role of binder and conductive additive all-inone allowing to increment the charge of active component and thus capacity of the electrode. Another interesting approach is the use of ionic conductive binders such as poly(ionic liquid)s or single-ion conducting polymers as binders. $\underline{\mathbf{8}}$ In this case the ion conductive binder facilitates the ion flux toward the electrode material, facilitating its charge and discharge. Last but not least, the use of redox polymers as active binders in hybrid electrodes is recently followed. In this case the polymer material acts as redox mediator and facilitates the fast charge of the inorganic electrode material. $\underline{9}$

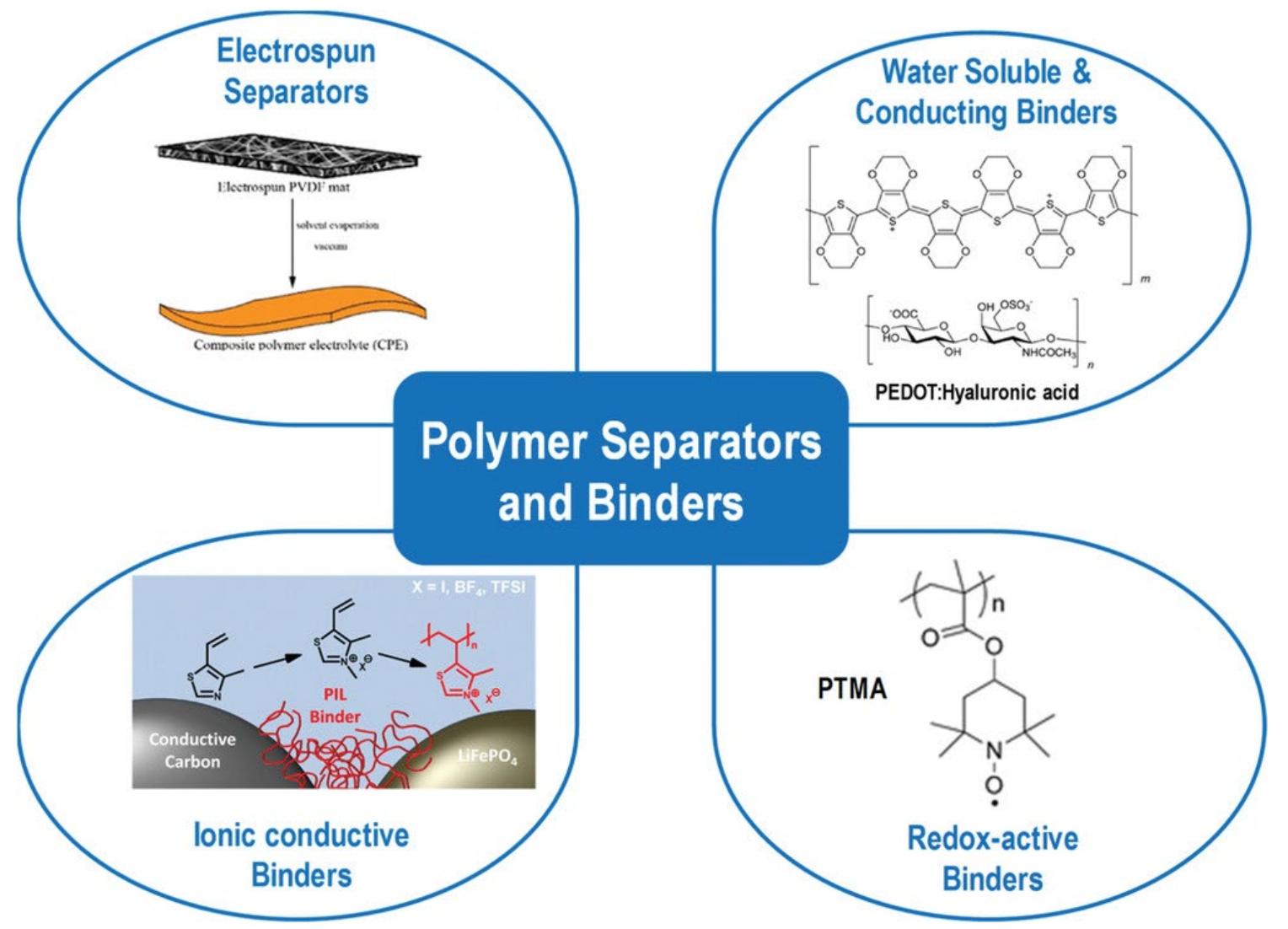

Figure 2. Trends in polymer materials for separator and binder applications in batteries. Reproduced with permission.3 Copyright 2019, American Chemical Society. 8 Copyright 2015, American Chemical Society. 
All in all, separators and binders are an important part of the battery that historically has been under-considered. For the time being, the need for optimization of the battery performance, as well as the need of more sustainable and green electrode fabrication methods is pushing the research. Furthermore, the emergence of advanced processing such as 3D printing or new functionalities requested to batteries such as flexibility and self-healing properties will clearly boost the future interest into innovative separators and functional polymer binders.

\section{Polymer Electrolytes}

Electrolytes based on organic solvents are currently used in lithium-ion batteries. However, they are unable to satisfy all requirements of next-generation batteries and are likely to be complemented, in the longer term by solid-state electrolytes. PEO incorporating a lithium salt has been the gold standard solid polymer electrolyte (SPE) in the area of lithium battery for more than 40 years.10 Nowadays, this technology is being implemented in batteries for electric vehicles where security is a must. The resurgence in SPE research has arisen from the impetus for safer technologies and, in particular, Li metal and the recognition that many applications benefit from elevated temperatures $\left(50-100^{\circ} \mathrm{C}\right.$ ) rather than room temperature. It is worth to note also that $95 \%$ of the research efforts in this area have been historically devoted to lithium. Due to the interest in new battery technologies such as sodium, zinc, calcium, or magnesium or fully organic batteries, all the solid electrolytes need to be adapted to each specific battery technology. These reasons are behind the worldwide efforts to develop new polymer electrolytes for the next-generation batteries including new SPEs, single-ion conducting block copolymers, poly(ionic liquid)s, and ionogels that will be exemplified in the next paragraphs.11

SPEs composed only of a polymer matrix and one metal salt are ideal for all-solid batteries. In this area PEO is the gold standard showing relatively high ionic conductivity at $70^{\circ} \mathrm{C}\left(\sigma=10^{-3} \mathrm{~S}\right.$ $\mathrm{cm}^{-1}$ ) although due to its high crystallinity it shows relatively low ionic conductivity at room temperature $\left(\sigma \leq 10^{-5} \mathrm{~S} \mathrm{~cm}^{-1}\right)$. For this reason, over the years many researchers have engineered ways to avoid the crystallinity of PEO in order to increase the performance at room temperature.12 In any case, the low values of ionic conductivity and the low lithium transference number ( $T_{L i} \approx 0.2$ ) of PEO are important barriers for room temperature battery operation. In this sense, aliphatic polycarbonates were recently suggested as alternatives to

PEO SPEs.13 Polycarbonate SPEs showed similar ionic conductivity values at high temperature but superior at room temperature as well as higher lithium transference numbers $\left(T_{\mathrm{Li}} \geq 0.5\right)$ than PEO which has allowed the room temperature operation of lithium-ion batteries. In Figure 3 we show some chemical structures that we recently reported synthesized polycondensation $\underline{14}$ as well as step-growth using $\mathrm{CO}_{2}$ as reagent, respectively. $\underline{15}$ 
A popular approach to further improve lithium transport numbers ( $T_{\mathrm{Li}+} \geq 0.8$ ) consists of anchoring the negatively charged ion to the polymeric chain, named then as single-ion conducting polymer electrolytes (SIPES). SIPEs are one of the most attractive alternatives for lithium metal anodes since they do not present concentration gradients during battery operation, which limits the lithium dendrite formation. Several SIPEs including weak anionic species have been investigated; the most studied SIPEs being the lithium poly(styrene sulfonyl(trifluoromethylsulfonyl)imide systems.16 This polymer and its methacrylic version have been included in a variety of block copolymer formulations combining it with PEO segments aiming to improve its ionic conductivity values.17 Nowadays, among the SIPES reported in the literature the triblock copolymers between PEO and methacrylic sulfonamide (Figure $\underline{3}$ ) showed the highest ionic conductivity values of $10^{-4} \mathrm{~S} \mathrm{~cm}^{-1}$ at $70{ }^{\circ} \mathrm{C}$ and lithium transference numbers close to unity. $\underline{18}$

Polymeric ionic liquids or poly(ionic liquid)s (PILs) containing both ionic liquid-like moieties and polymer frameworks are emerging as alternative polymers in energy owing to their various intrinsic features, such as superior mechanical and chemical stability, structural controllability over the ionic species, and macromolecular backbone.19 PILs are currently being investigated as matrices for polymer-in-salt electrolytes. Polymers-in-salt are solid electrolytes mostly composed of a lithium salt within a minor polymer matrix. This area is being revisited as a way to have high ionic conductive SPEs with relatively high lithium transference number and electrochemical window. We recently showed a poly diallyldimethylammonium FSI (PDADMA FSI) electrolyte for application in safe lithium-metal batteries. As a proof of concept, the polyILin-salt with optimal composition shows promising full-cell cycling performance at elevated temperature, especially when high loading of the high voltage cathode $\mathrm{Li}_{1 / 3} \mathrm{Ni}_{1 / 3} \mathrm{Mn}_{1 / 3} \mathrm{CoO}_{2}$ is used. The proposed system provides a new strategy for the development of highly efficient, solvent-free, SPEs with improved safety characteristics. $\underline{20}$

PDADMA-TFSI-based poly(ionic liquid) of high molecular weight polymer is commonly used in combination with an ionic liquid electrolyte to form an ionogel free-standing membrane. By this simple method, polymer ionogel electrolytes can be engineered for being used in rechargeable lithium metal, $\underline{21}$ sodium metal, $\underline{22}$ zinc batteries $\underline{23}$ as well as supercapacitors.24 The poly(ionic liquid) gives the mechanical properties and the good interaction with the ionic liquid avoiding its leaching, whereas the ionic liquid confers to the material the high values of ionic conductivity for the different applications $\left(\sigma>10^{-3} \mathrm{~S} \mathrm{~cm}^{-1}\right.$ at room temperature). As a limitation once the ionic liquid content is higher than $50 \mathrm{wt} \%$ the ionic liquid/poly(ionic liquid) material becomes too soft to form a free-standing membrane. For this reason, we recently developed two new polymeric approaches i) a polyethylene glycol network 
obtained by photopolymerization $\underline{25}$ and ii) a new synthetic route toward PS- $b$-PDADMA-PS triblock copolymers by polymerization induced self-assembly (PISA).26 Using both approaches it was possible to form free-standing ionogel membranes with more than 80 wt\% of the ionic liquid component. This allows to increase the ionic conductivity values of the ionogel polymer electrolytes by one order of magnitude and to boost the performance of the batteries.

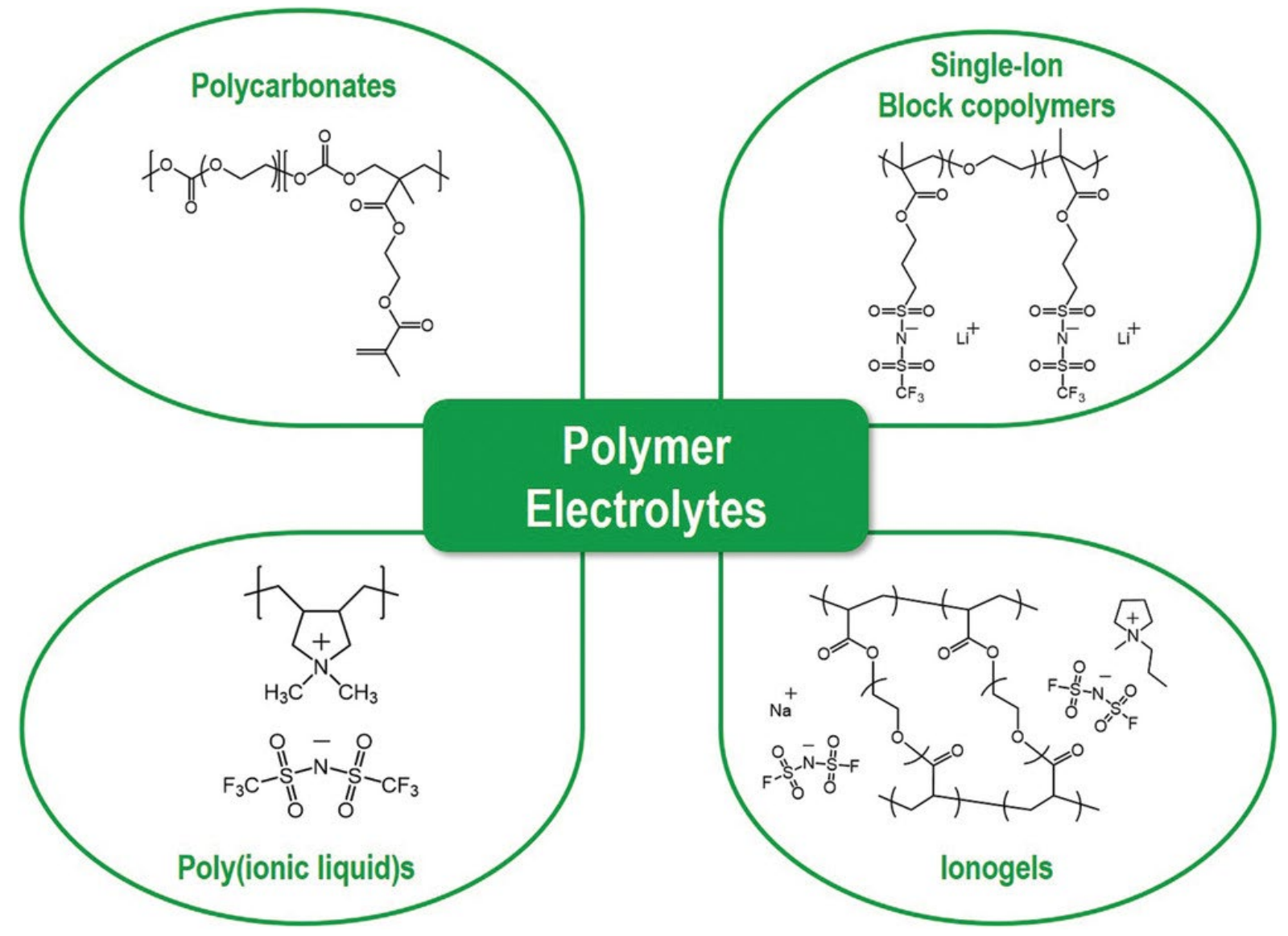

Figure 3. Trends in polymer chemistries for solid electrolyte applications in batteries.

To sum up, different polymer electrolytes have been developed in the past years mostly driven by the interest in lithium metal batteries. Most of the works were initially centered in PEO although in the past years alternative polymers have strongly emerged as the ones described in the previous paragraphs. However, it is difficult to anticipate a winner in this race. The main reason for this is that requirements of the next-generation batteries based on new lithium cathodes, sodium, zinc, calcium or magnesium, or fully organic batteries in terms of ionic conductivity, ion transference numbers, or electrochemical window will be very different for each technology. In the near future, most of the advances may come from adapting the concepts already developed for lithium-ion batteries to the next-generation battery technologies. However, all the problems of lithium metal batteries such as dendrite formation are still not fully solved which anticipates that new polymers and concepts will be also required. 


\section{Redox Polymers}

Polymers with redox properties are electroactive macromolecules containing localized sites or groups that can be reversibly oxidized and reduced. Nowadays, redox polymers are becoming promising alternatives as substitutes of inorganic redox materials as cathodic or anodic electrode active materials. It is worth mentioning that, in the past, the requirements for electrode materials have been only focused on the efficiency of the device such as capacity, energy density, or cyclability and, of course, their safety. Nevertheless, the current challenge is to be able to build efficient and safe batteries from a green and sustainable chemistry standpoint. Thus, redox-active polymers may offer not only a promising solution in terms of energy storage but also, as long as they are synthesized from biomass and/or can be recycled, in terms of sustainable batteries. $\underline{27}$

Polymeric materials possess additional features such as lower specific weight, low solubility, mechanical and thermal stability as well as low toxicity that make them interesting materials for electrodes. Incorporation of redox polymers in batteries started with electrically conducting polymers such as polyacetylene and polyaniline. They were followed by polymers containing stable radicals known as radical polymers, 28 such as nitroxides and galvinoxyls and by sulfurcontaining polymers. Organic carbonyl polymers $\underline{29}$ have emerged as a new type of redox polymer for batteries including quinone-functional polymers, polyimides. In the next paragraphs, we will highlight some recent developments within these four redox polymer families.

The first example of redox polymer is the PEDOT-TEMPO derivative shown in Figure $\underline{4}$. This polymer combines the most successful conducting polymer backbone PEDOT together with the redox activity of the nitroxide stable radical. The polymer was successfully applied as conductive active binder in LFP cathodes, $\underline{30}$ as well as cathode material in lithium-based organic batteries showing relatively good capacity and stability. $\underline{31}$

Among the carbonyl-containing polymers, the most attractive ones are benzoquinonecontaining polymers because of their high theoretical capacity (up to $496 \mathrm{~mA} \mathrm{~h} \mathrm{~g}^{-1}$ ) and their high redox potential at around $2.8 \mathrm{~V}$ ( $p$-benzoquinone) until $3.0 \mathrm{~V}$ (o-quinones) versus $\mathrm{Li} / \mathrm{Li}^{+}$. Furthermore, benzoquinones are abundant in nature, which makes them quite interesting in terms of sustainability. In a seminal work, Inganäs et al. reported the use of hybrids between conducting polymers such as polypyrrole and natural ones such as lignosulfonates as electrode materials for supercapacitors. 32 Later on, some of us reported the use of PEDOT/lignin hybrids as more stable electrode materials for batteries and supercapacitors.33 More recently, Detrembleur and co-workers used catechol-containing linear copolymers for battery cathodes 
with a record energy density of $1200 \mathrm{~W} \mathrm{~h} \mathrm{~kg}^{-1}$. $\underline{34}$ Furthermore, it was recently demonstrated that catechol groups could be considered as a universal host for aqueous rechargeable batteries based on different cations from monovalent, divalent, and trivalent ones $\left(\mathrm{H}^{+}, \mathrm{Li}^{+}, \mathrm{K}^{+}\right.$, $\mathrm{Zn}^{2+}, \mathrm{Mg}^{+2}, \mathrm{Ca}^{+2}$, and $\left.\mathrm{Al}^{3+}\right) . \underline{35}$ Our group recently reported the synthesis of redox-active polymer nanoparticles based on this bioinspired catechol polymer chemistry which could be used in a number of battery technologies. $\underline{36}$

Another interesting polymer family among the carbonyl-containing ones are polyimides. Polyimides are well-known high-performance polymers whose use is in high demanding applications in aerospace and electronics. $\mathbf{3 7}$ In the past years they were investigated due to its redox properties as electrode materials for lithium and sodium batteries, as well as redoxactive binders in lithium sulfur cells mainly. $\underline{\mathbf{3 8}}$ Recently, the dual redox-active phenothiazinenaphthalene polyimide, as the one shown in Figure $\underline{4}$, has been applied simultaneously as cathode and anode material in a symmetric all-organic battery with high power densities, demonstrating an efficient strategy to develop polymer electrodes and symmetric configurations for next-generation all-polymer batteries. $\underline{38}$

Among the different types of redox polymers based on sulfur chemistry, the high-sulfur content copolymers synthesized by inverse vulcanization developed by Pyun et al. is receiving a great deal of attention in the past years. 39 High-sulfur-containing polymers are interesting cathodic materials to substitute sulfur in lithium sulfur cells with good cyclability. Among the different copolymers developed in the past years, we would like to highlight here the ones obtained by inverse vulcanization between sulfur and naturally occurring dienes. 40 The sulfurnatural diene copolymers consisting of cheap and abundant chemicals are an excellent option of sustainable materials for electrochemical energy storage due to their good capacity retention and cyclability. Another example includes the combination of sulfur copolymers with anthraquinone redox groups as recently proposed in the synthesis of poly(anthraquinonyl sulfide)s shown in Figure $\underline{4}$. This polymer combines the known and reversible redox chemistry of anthraquinone moieties with the high capacity values of sulfur. 41

To conclude this part, in the last decade different families of redox polymers are being developed in parallel including conducting polymers, radical polymers, carbonyl-containing polymers and sulfur-containing polymers. These polymers can be classified in terms of theoretical capacity values and redox voltage for assessing their energy storage capacity. Furthermore, they can be used in a number of different battery technologies (metal-polymer, all polymer, redox-flow batteries). However, it makes the benchmarking of the different polymers very difficult and aspects like self-discharge, cyclability and durability of the batteries, and sustainability and prize of the polymers also need to be taken into account. 


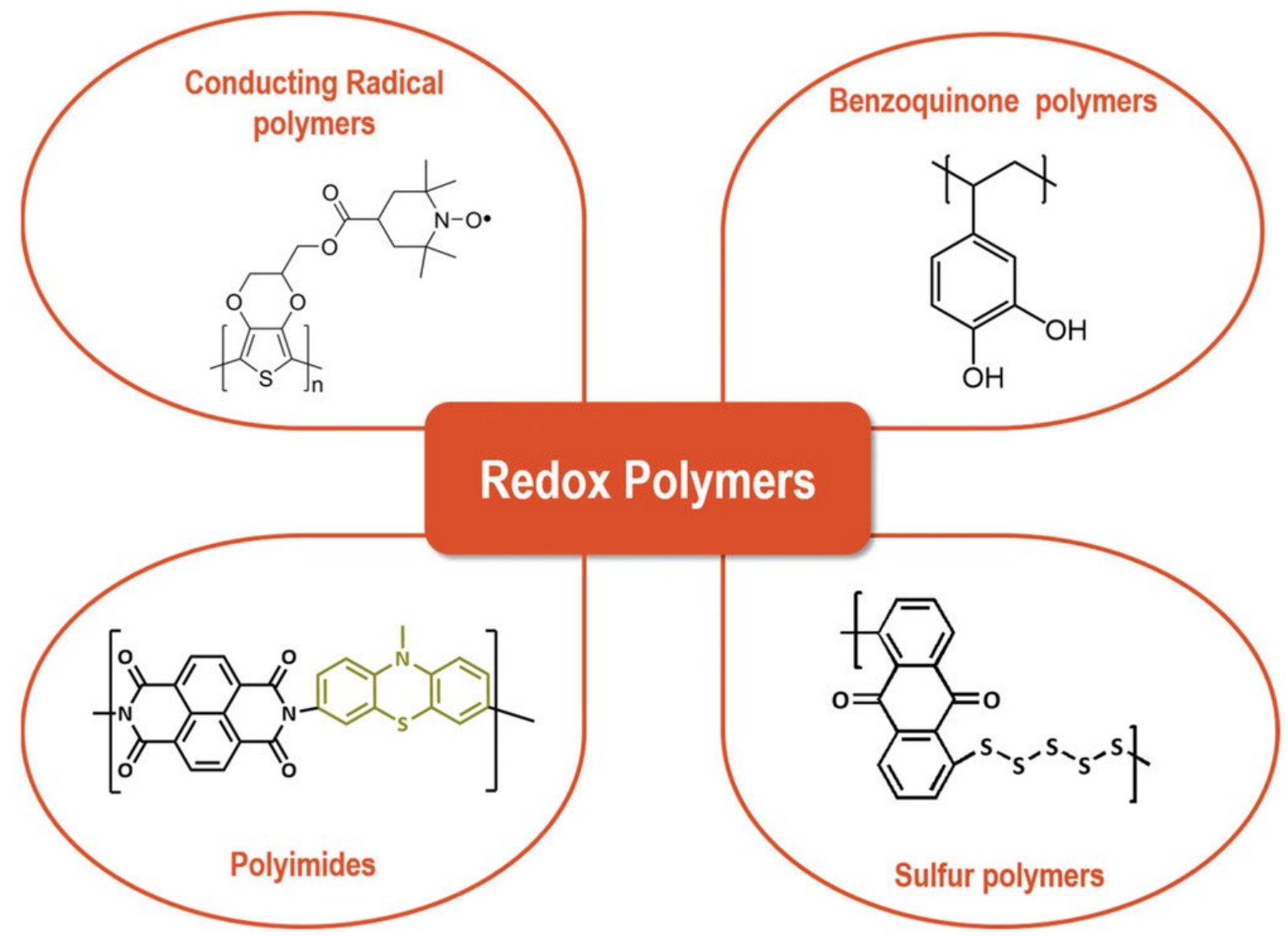

Figure 4. Trends in redox polymers as electroactive materials in battery electrodes.

\section{Outlook}

In this article, we review some of the recent developments in the area of innovative polymers for electrochemical energy storage. In particular we highlighted some examples of polymers and trends in the area of separators, polymer binders, polymer electrolytes, and redox polymers. We highlighted recent developments in the area of redox-active, electronic/ionic conducting polymers which may serve as examples of the actual trends in the area. All these new polymer developments are leading to new battery technologies such as the full development of organic batteries, 3D printed batteries, new polymer air cells, and new types of redox flow battery technologies, which should make it to the market in the near future.

\section{Acknowledgements}

Financial support from the Basque Government, Spanish Government and the European Research Council by Starting Grant Innovative Polymers for Energy Storage (iPes) 306250 is acknowledged. L.P. has received funding from the European Union's Horizon 2020 research and innovation programme under the Marie Skłodowska-Curie grant agreement No 797295.

\section{Conflict of Interest}

The authors declare no conflict of interest. 


\section{Biographies}

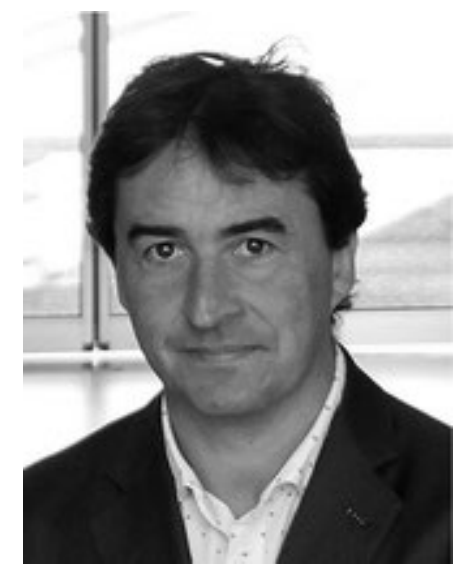

David Mecerreyes is an Ikerbasque research professor at the University of the Basque Country. $\mathrm{He}$ is the head of the Innovative Polymers Group and scientific vice-director at POLYMAT. His research interests focuses on the synthesis of innovative polymers for emerging applications including poly(ionic liquid)s, redox polymers for organic batteries, and conducting polymers for bioelectronics.

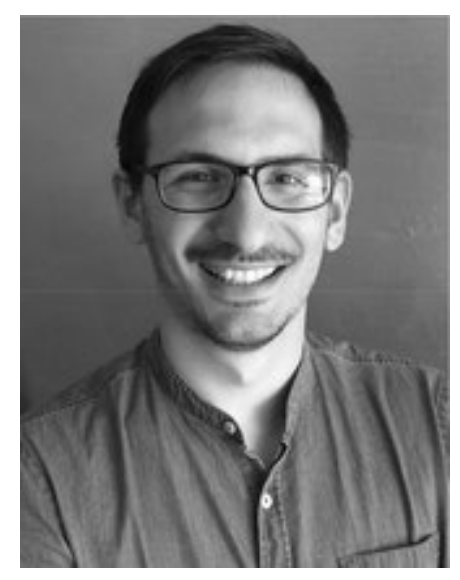

Luca Porcarelli is a Marie Skłodowska-Curie Fellow at the Institute for Frontier Materials, Deakin University and POLYMAT, University of the Basque Country. He obtained his Ph.D. in material science from the Polytechnic of Turin, in 2016. His research interests focus on the synthesis of polymer electrolytes and organic ionic plastic crystals for applications in energy storage and bioelectronics. 


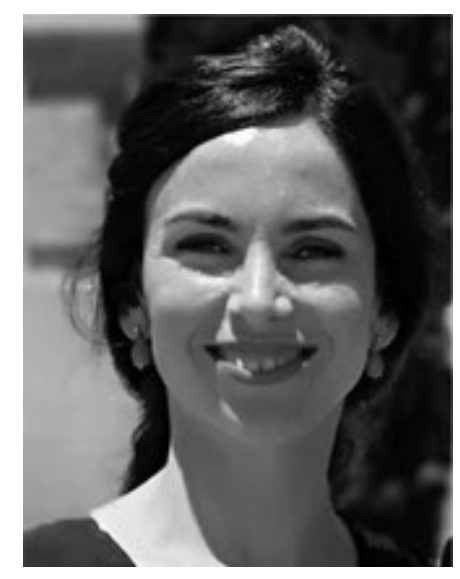

Nerea Casado is a postdoctoral researcher at the University of the Basque Country, Spain. She completed her Ph.D. in applied chemistry and polymeric materials in 2017 working on the development of innovative poly(3,4-ethylenedioxythiophene) materials for electrochemical energy storage. Her current research interests include redox polymers, conducting polymers, organic ionic plastic crystals, and functional composite materials for energy storage and bioelectronics.

\section{REFERENCES}

[1] a) Nobel Media AB, www.nobelprize.org/prizes/chemistry/2019/ press-release/ (accessed: October 2019); b) M. S. Whittingham, J. Chem. Soc., Chem. Commun. 1974, 328; c) K. Mizushima, P. C. Jones, P. J. Wiseman, J. B. Goodenough, Mater. Res. Bull. 1980, 15, 783; d) A. Yoshino, K. Sanechika, T. Nakajima, Jap 1989293, 1985.

[2] M. Armand, J. M. Tarascon, Nature 2008, 451, 652.

[3] a) Y. Li, Q. Li, Z. Tan, J. Power Sources 2019, 443, 227262; b) M. Liu, N. Deng, J. Ju, L. Fan, L. Wang, Z. Li, H. Zhao, G. Yang, W. Kang, www.advancedsciencenews.com J. Yan, B. Cheng, Adv. Funct. Mater. 2019, 29, 1905467; c) X. Wang, G. M. A. Girard, H. Zhu, R. Yunis, D. R. MacFarlane, D. Mecerreyes, A. J. Bhattacharyya, P. C. Howlett, M. Forsyth, ACS Appl. Energy Mater. 2019, 2, 6237.

[4] Green Lion. http://www.greenlionproject.eu/homepage (accessed: January 2020)

[5] D. Bresser, D. Buchholz, A. Moretti, A. Varzi, S. Passerini, Energy Environ. Sci. 2018, 11, 3096.

[6] M. A. Spreafico, P. Cojocaru, L. Magagnin, F. Triulzi, M. Apostolo, Ind. Eng. Chem. Res. 2015, 53, 90094.

[7] D. Cintora-Juarez, C. Perez-Vicente, S. Ahmad, J. L. Tirado, RSC Adv. 2014, 4, 26108. 
[8] a) J. Von Zamory, M. Bedu, S. Fantini, S. Passerini, E. Paillard, J. Power Sources 2013, 240, 745; b) K. Grygiel, J.-S. Lee, K. Sakaushi, M. Antonietti, J. Yuan, ACS Macro Lett. 2015, 4, 1312.

[9] A. Vlad, N. Singh, J. Rolland, S. Melinte, P. M. Ajayan, J. F. Gohy, Sci. Rep. 2015, 4, 4315.

[10] M. Armand, Solid State Ionics 1994, 69, 309.

[11] M. Forsyth, L. Porcarelli, X. Wang, N. Goujon, D. Mecerreyes, Acc. Chem. Res. 2019, 52, 686.

[12] a) I. Aldalur, M. Armand, H. Zhang, Batteries Supercaps 2020, 3, 30; b) D. Rosenbach, N. Mödl, M. Hahn, J. Petry, M.A. Danzer, M. Thelakkat, ACS Appl. Energy Mater. 2019, 2, 3373;

[13] J. Mindemark, M. J. Lacey, T. Bowden, D. Brandell, Prog. Polym. Sci. 2018, 81, 114.

[14] a) L. Meabe, N. Lago, L. Rubatat, C. Li, A. J. Müller, H. Sardon, M. Armand, D. Mecerreyes, Electrochim. Acta 2017, 237, 259; b) L. Meabe, T. V. Huynh, N. Lago, H. Sardon, C. Li, L. A. O’Dell, M. Armand, M. Forsyth, D. Mecerreyes, Electrochim. Acta 2018, 264, 367; c) L. Meabe, T. V. Huynh, D. Mantione, L. Porcarelli, C. Li, L. A. O’Dell, H. Sardon, M. Armand, M. Forsyth, D. Mecerreyes, Electrochim. Acta 2019, 302, 414.

[15] F. Ouhib, L. Meabe, A. Mahmoud, N. Eshraghi, B. Grignard, J.-M. Thomassin, A. Aqil, F. Boschini, C. Jérôme, D. Mecerreyes, C. Detrembleur, J. Mater. Chem. A 2019, 7, 9844.

[16] H. Zhang, C. Li, M. Piszcz, E. Coya, T. Rojo, L. M. Rodriguez- Martinez, M. Armand, Z. Zhou, Chem. Soc. Rev. 2017, 46, 797.

[17] R. Bouchet, S. Maria, R. Meziane, A. Aboulaich, L. Lienafa, J.-P. Bonnet, T. N. T. Phan, D. Bertin, D. Gigmes, D. Devaux, R. Denoyel, M. Armand, Nat. Mater. 2013, 12, 452.

[18] a) L. Porcarelli, P. S. Vlasov, D. O. Ponkratov, E. I. Lozinskaya, D. Y. Antonov, J. R. Nair, C. Gerbaldi, D. Mecerreyes, A. S. Shaplov, Eur. Polym. J. 2018, 107, 218; b) L. Porcarelli, M. A. Aboudzadeh, L. Rubatat, J. R. Nair, A. S. Shaplov, C. Gerbaldi, D. Mecerreyes, J. Power Sources 2017, 364, 191; c) L. Porcarelli, K. Manojkumar, H. Sardon, O. Llorente, A. S. Shaplov, K. Vijayakrishna, C. Gerbaldi, D. Mecerreyes, Electrochim. Acta 2017, 241, 526; d) L. Porcarelli, A. S. Shaplov, F. Bella, J. R. Nair, D. Mecerreyes, C. Gerbaldi, ACS Energy Lett. 2016, 14, 678; e) L. Porcarelli, A. S. Shaplov, M. Salsamendi, F. Bella, J. R. Nair, Y. S. Vygodskii, D. Mecerreyes, C. Gerbaldi, ACS Appl. Mater. Interfaces 2016, 8, 10350.

[19] G. G. Eshetu, D. Mecerreyes, M. Forsyth, H. Zhang, M. Armand, Mol. Syst. Des. Eng. 2019, 4, 294.

[20] X. Wang, F. Chen, G. M. A. Giraud, H. Zhou, D. R. MacFarlane, D. Mecerreyes, M. Armand, P. C. Howlett, M. Forsyth, Joule 2019, 3, 2687.

[21] G. B. Appetecchi, G.-T. Kim, M. Montanino, M. Carewska, R. Marcilla, D. Mecerreyes, I. De Meatza, J. Power Sources 2010, 195, 3668. 
[22] A. Fdz De Anastro, N. Lago, C. Berlanga, M. Galcerán, M. Hilder, M. Forsyth, D. Mecerreyes, J. Membr. Sci. 2019, 582, 435.

[23] A. Fdz De Anastro, N. Casado, X. Wang, J. Rehmen, D. Evans, D. Mecerreyes, M. Forsyth, C. Pozo-Gonzalo, Electrochim. Acta 2018, 278, 271.

[24] a) E. Senokos, V. Reguero, L. Cabana, J. Palma, R. Marcilla, J.-J. Vilatela, Adv.Mater. Technol. 2017, 2, 1600290; b) G. A. Tiruye, D. Muñoz-Torrero, J. Palma, M. Anderson, R. Marcilla, J. Power Sources 2016, 326, 560; c) G. A. Tiruye, D. Muñoz-Torrero, J. Palma, M. Anderson, R. Marcilla, J. Power Sources 2015, 279, 472.

[25] A. Fdz De Anastro, L. Porcarelli, M. Hilder, C. Berlanga, M. Galceran, P. Howlett, M. Forsyth, D. Mecerreyes, ACS Appl. Energy Mater. 2019, 2, 6960.

[26] a) I. Aldalur, M. Armand, H. Zhang, Batteries Supercaps 2020, 3, 30.

[27] a) N. Casado, G. Hernández, H. Sardon, D. Mecerreyes, Prog. Polym. Sci. 2016, 52, 107; b) F. N. Ajjan, D. Mecerreyes, O. Inganäs, Biotechnol. J. 2019, 14, 1900062.

[28] a) K. Oyaizu, H. Nishide, Adv. Mater. 2009, 21, 2339; b) T. Janoschka, M. D. Hager, U. S. Schubert, Adv. Mater. 2012, 24, 6397.

[29] K. Amin, L. Mao, Z. Wei, Macromol. Rapid Commun. 2019, 40, 1800565.

[30] N. Casado, G. Hernández, A. Veloso, S. Devaraj, D. Mecerreyes, M. Armand, ACS Macro Lett. 2016, 5, 59.

[31] P.-O. Schwartz, M. Pejic, M. Wachltler, P. Bauerle, Synth. Met. 2018, 243, 51.

[32] G. Milczarek, O. Inganäs, Science 2012, 335, 1468.

[33] F. N. Ajjan, N. Casado, T. Re ، bis', A. Elfwing, N. Solin, D. Mecerreyes, O. Inganäs, J. Mater. Chem. A 2016, 4, 1838.

[34] N. Patil, A. Aqil, F. Ouhib, S. Admassie, O. Inganäs, C. Jérôme, C. Detrembleur, Adv. Mater. 2017, 29, 1703373.

[35] N. Patil, A. Mavrandonakis, C. Jérôme, C. Detrembleur, J. Palma, R. Marcilla, ACS Appl. Energy Mater. 2019, 2, 3035.

[36] K. Pirnat, N. Casado, L. Porcarelli, N. Ballard, D. Mecerreyes, Macromolecules 2019, 52, 8155.

[37] B. Baumgartner, M. J. Bojdys, M. M. Unterlaas, Polym. Chem. 2014, 5, 3771.

[38] a) G. Hernández, N. Casado, R. Coste, D. Shanmukaraj, L. Rubatat, M. Armand, D. Mecerreyes, RSC Adv. 2015, 5, 17096; b) G. Hernández, M. Salsamendi, S. M. Morozova, E. I. Lozinskaya, S. Devaraj, Y. S. Vygodskii, A. S. Shaplov, D. Mecerreyes, J. Polym. Sci., Part A: Polym. Chem. 2018, 56, 714; c) N. Casado, D. Mantione, D. Shanmukaraj, D. Mecerreyes, 
ChemSusChem 2019, https:// doi.org/10.1002/cssc.201902856; d) G. Hernández, N. Lago, D. Shanmukaraj, M. Armand, D. Mecerreyes, Mater. Today Energy 2017, 6, 264.

[39] W. J. Chung, J. J. Griebel, E. T. Kim, H. Yoon, A. G. Simmonds, H. J. Ji, P. T. Dirlam, R. S. Glass, J. J. Wie, N. A. Nguyen, B. W. Guralnick, J. Park, Á. Somogyi, P. Theato, M. E. Mackay, Y.E. Sung, K. Char, J. Pyun, Nat. Chem. 2013, 5, 518.

[40] I. Gomez, O. Leonet, J. A. Blazquez, D. Mecerreyes, ChemSusChem 2016, 9, 3419.

[41] I. Gomez, O. Leonet, J. A. Blazquez, H.-G. Grande, D. MecerreyesACS Macro Lett. 2018, 7, 419 . 